\title{
Pengaruh Kadar Fly Ash terhadap Kuat Tekan (f'c) Material pada High Volume Fly Ash-Self Compacting Concrete (HVFA-SCC) Usia 28 Hari
}

\author{
Karina Puspa Amalia'), Agus Setiya Budi2), Sunarmasto ${ }^{3)}$ \\ 1) Mahasiswa Program Studi Teknik Sipil Fakultas Teknik Universitas Sebelas Maret \\ 2),3) Pengajar Program Studi Teknik Sipil Fakultas Teknik Universitas Sebelas Maret \\ Jl. Ir. Sutami 36 A, Kentingan Surakarta 57126. Telp (0271) 647069, Fax 662118 \\ Email:karinapuspaamalia@gmail.com
}

\begin{abstract}
Fly ash is a coal combustion waste, having chemical content that is $80 \%$ silica and alumina. These compounds react with $\mathrm{Ca}(\mathrm{OH})_{2}$ from cement hydration process forming $\mathrm{C}_{3} \mathrm{~S}_{2} \mathrm{H}_{3}$ or tubermorite that can increase concrete compressive strength. Physically, fly ash has a nearly spherical shape that has a ball bearing effect on the plane of mortar. Fly ash as a cement subtituent often used in large proportion (>50\%). These concept called High Volume Fly Ash Concrete (HVFAC). Overcoming problem from forming hole in reinforced concrete, HVFA-SCC is combined with Self Compacting Concrete (SCC). This research will be studied about the effect of fly ash content to compressive strength on HVFA-SCC. This study using experimental method, which used 3 variation of fly ash content in HVFA-SCC 50\%, 60\%, 70\% and normal concrete as comparator. Each variation consist of $375 \mathrm{~mm} \times 150 \mathrm{~mm}$ sample. These sample will be equated based on grade that is $40 \mathrm{MPa}$. Fresh concrete were characteristics by 3 methods: flow table test, L-box test, and $V$-funnel test. The result of the test showed that workability of concrete increasing with the increasing of fly ash replacement ratio. Testing of hardened concrete was conducted to get value of concrete's stress. The result for HVFA.28.50, HV FA.28.60, HVFA.28.70, and NC.28 are 49,86 MPa, 39,16 MPa, 23,71 MPa, dan 47,78 MPa. From the result of this researches can be concluded that the higher fly ash content decrease the value of compressive strength. That can be happened because not only main bonding material decreased but also fly ash hasn't been reacted optimally at 28 days.
\end{abstract}

Keyword : compressive strength, fly ash, HVFA-SCC

\begin{abstract}
Abstrak
Fly ash merupakan limbah pembakaran batu bara yang memiliki kandungan kimia berupa silika dan alumina mencapai $80 \%$. Senyawa tersebut bereaksi dengan $\mathrm{Ca}(\mathrm{OH})_{2}$ hasil proses hidrasi semen dan membentuk $\mathrm{C}_{3} \mathrm{~S}_{2} \mathrm{H}_{3}$ atau tubermorite yang dapat menambah kekuatan beton. Secara fisik fly ash memiliki bentuk yang hampir bulat semppurna sehingga memiliki ball bearing effect pada bidang gelincir adukan mortar atau semen. Fly ash sebagai subtituen semen sering digunakan dalam jumlah besar (>50\%). Konsep tersebut dikenal dengan High Volume Fly Ash Concrete (HVFAC). Untuk mengatasi permasalahan terbentuknya rongga pada beton bertulang, konsep HVFAC dipadukan dengan Self Compacting Concrete (SCC). Penelitian ini mengkaji pengaruh persentase fly ash terhadap kuat tekan pada beton HVFA-SCC. Metode penelitian ini adalah eksperimen, dimana digunakan 3 variasi kadar fly ash pada beton HVFA-SCC yaitu 50\%, 60\%, 70\% serta beton normal. Tiap variasi terdiri dari 3 sampel berukuran $75 \mathrm{~mm}$ x $150 \mathrm{~mm}$. Pengujian beton segar HVFA-SCC dilakukan dengan 3 metode yaitu : flow table test, L-box test, dan V-funnel test. Hasil pengujian menunjukkan bahwa semakin bertambahnya kadar fly ash maka workability dari beton segar tersebut semakin baik. Pengujian beton keras dilakukan untuk mendapatkan nilai kuat tekan beton. Kuat tekan yang dihasilkan HVFA.28.50, HVFA.28.60, HVFA.28.70, dan NC.28 berturut turut adalah 49,86 $\mathrm{MPa}, 39,16 \mathrm{MPa}, 23,71 \mathrm{MPa}$, dan 47,78 $\mathrm{MPa}$. Dari hasil pengujian tersebut dapat disimpulkan bahwa semakin banyak penambahan kadar fly ash maka kuat tekan semakin menurun. Hal tersebut diakibatkan karena tidak hanya menurunnya bahan ikat utama beton tetapi juga fly ash belum bereaksi secara optimal pada usia 28 hari.
\end{abstract}

Kata Kunci : kuat tekan, fly ash, HVFA-SCC

\section{PENDAHULUAN}

Perkembangan industri konstruksi di Indonesia saat ini semakin pesat, baik dalam hal inovasi metode pelaksanaan, material, maupun ilmu pengetahuan yang berkontribusi terhadap perbaikan kinerja serta produktivitas di industri konstruksi. Beton menjadi hal yang tidak dapat dipisahkan dari dunia konstruksi. Meningkatnya produksi semen Portland berkontribusi terhadap timbulnya efek rumah kaca (green house effect) dan memicu terjadinya pemanasan global (global warming), mengingat proses produksi satu ton semen menghasilkan $\mathrm{CO}_{2}$ setara dengan 0,55 ton dan memerlukan bahan bakar karbon yang akan menghasilkan emisi $\mathrm{CO}_{2}$ sebanyak 0,45 ton (Davidovits, 1994). Beberapa penelitian telah dilakukan untuk membuat suatu campuran yang ramah lingkungan. Salah satunya adalah dengan cara mengurangi dan mengganti penggunaan semen yang notabene merupakan polutan terbesar. Material yang umum digunakan sebagai pengganti semen adalah fly ash. Dalam beberapa penelitian, fly ash digunakan sebagai substituen semen dengan kadar yang cukup besar ( $>50 \%)$ dari 
berat semen. Konsep tersebut dikenal dengan High Volume Fly Ash Concrete (HVFAC). Untuk mengatasi permasalahan terbentuknya rongga pada beton bertulang, konsep HVFAC dipadukan dengan Self Compacting Concrete (SCC). Penelitian ini menggunakan variasi persentase fly ash untuk mengetahui kuat tekan pada High Volume Fly Ash Self Compacting Concrete (HVFA-SCC) benda uji silinder D 7,5cm x $15 \mathrm{~cm}$ usia 28 hari.

\section{DASAR TEORI}

\section{Reaksi Kimia}

Reaksi kimia utama yang terjadi di dalam beton yaitu hidrasi $\mathrm{C}_{3} \mathrm{~S}$ dan $\mathrm{C}_{2} \mathrm{~S}$ ditunjukkan dengan reaksi kimia di bawah ini :

\begin{tabular}{|c|c|c|c|c|}
\hline $2\left(3 \mathrm{CaO} \cdot \mathrm{SiO}_{2}\right)$ & $+6 \mathrm{H}_{2} \mathrm{O}$ & Cepat & $3 \mathrm{CaO} \cdot \mathrm{SiO}_{2} \cdot 3 \mathrm{H}_{2} \mathrm{O}$ & $+3 \mathrm{Ca}(\mathrm{OH})_{2}$ \\
\hline $2 \mathrm{C}_{3} \mathrm{~S}$ & $+6 \mathrm{H}$ & Cepat & C-S-H gel & $+3 \mathrm{CH}$ \\
\hline Trikalsium silikeat & & & gel tobermorite & kalsium bidroksida \\
\hline $2\left(2 \mathrm{CaO} \cdot \mathrm{SiO}_{2}\right)$ & $+4 \mathrm{H}_{2} \mathrm{O}$ & Cepat & $3 \mathrm{CaO} \cdot \mathrm{SiO}_{2} \cdot 3 \mathrm{H}_{2} \mathrm{O}$ & $+\mathrm{Ca}(\mathrm{OH})_{2}$ \\
\hline $2 \mathrm{C}_{2} \mathrm{~S}$ & $+4 \mathrm{H}$ & Cepat & C-S-H gel & $+\mathrm{CH}$ \\
\hline kalsin & & & gel tobermorite & kalsium hidn \\
\hline
\end{tabular}

Keberadaan $\mathrm{Ca}(\mathrm{OH})_{2}$ di dalam mortar/beton akan bersifat merugikan dan menurunkan kuat tekan. Hal ini karena $\mathrm{Ca}(\mathrm{OH})_{2}$ dalam beton mudah sekali bereaksi dengan asam membentuk garam yang berdampak pada pengeroposan beton. Dengan penambahan fly ash yang mengandung senyawa silika $\left(\mathrm{SiO}_{2}\right)$ dapat mengeliminir $\mathrm{Ca}(\mathrm{OH})_{2} \cdot \mathrm{SiO}_{2}$ bereaksi dengan $\mathrm{Ca}(\mathrm{OH})_{2}$ membentuk $\mathrm{CSH}\left(3 \mathrm{CaO} \cdot \mathrm{SiO}_{2} \cdot 3 \mathrm{H}_{2} \mathrm{O}\right)$ yaitu senyawa utama pembangun kekuatan beton. Reaksi tersebut tersebar merata pada seluruh tempat di dalam beton termasuk pada ruang-ruang kosong pada lapisan agregat-pasta semen, sehingga menambah kekuatan lekatan antara agregat-pasta semen. Hal ini akan menambah kuat tekan beton, tetapi reaksi antara silica dengan kapur berlangsung sangat lambat, sehingga diperlukan waktu umur yang cukup lama untuk mencapai hasil kuat tekan yang optimal. Berikut adalah reaksi reaksi kimia $\mathrm{Ca}(\mathrm{OH})_{2}$ dengan $\mathrm{SiO}_{2}$ :

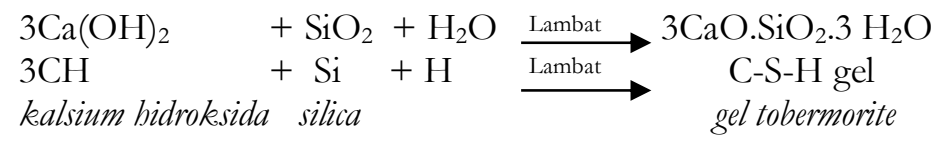

\section{Tegangan Beton}

$\sigma=\frac{F}{A}$

dengan :

$\sigma \quad=$ tegangan beton benda uji silinder $(\mathrm{MPa})$

$\mathrm{F} \quad=$ gaya desak maksimum $(\mathrm{N})$

A $\quad=$ luas permukaan benda uji silinder $\left(\mathrm{mm}^{2}\right)$

\section{METODE PENELITIAN}

Metode penelitian dalam penelitian ini adalah eksperimental yang dilakukan di Laboratorium Bahan, Laboratorium Struktur, dan Laboratorium Teknik Mesin Fakultas Teknik Universitas Sebelas Maret. Benda uji yang digunakan dalam penelitian ini berbentuk sillinder berukuran $7,5 \mathrm{~cm}$ x $15 \mathrm{~cm}$ dengan variasi jumlah kadar fly ash 50\%, 60\%, 70\%, dan 0\% (beton normal). Tiap variasi terdiri dari 3 sampel. Pengujian yang dilakukan adalah pengujian kuat desak menggunakan UTM (Universal Testing Machine). Selanjutnya data hasil pengujian tersebut akan diolah menggunakan Microsoft Excel.

\section{HASIL DAN PEMBAHASAN}

\section{Hasil Pengujian Material}

Agregat kasar dan halus yang digunakan dalam penelitian ini berasal dari Kulon Progo. Sedangkan Fy Ash berasal dari PLTU Paiton. Pengujian agregat dilakukan di Laboratorium Bahan dan Struktur Universitas Sebelas Maret. Pada agregat halus pengujian yang dilakukan adalah kandungan lumpur dalam pasir, kandungan zat organik dalam pasir, spesific gravity agregat halus (SNI 1970 2008) dan gradasi agregat halus (ASTM C136 ). Pada agregat kasar pengujian yang dilakukan adalah spesific gravity agregat kasar (SNI-1969-2008), abrasi agregat kasar (SNI2417-2008), gradasi agregat kasar (ASTM C136). Sedangkan material fly ash dilakukan pengujian XRF (X-Ray Fluorescence) di Laboratorium MIPA Terpadu Universitas Sebelas Maret. Hasil pengujian masing-masing material dapat dilihat pada tabel berikut : 
Tabel 1. Hasil Pengujian Agregat Kasar

\begin{tabular}{ccccc}
\hline No & Jenis Pengujian & Hasil Pengujian & Standar & Kesimpulan \\
\hline 1 & Absorbtion & $0,83 \%$ & - & - \\
\hline 2 & Apparent Specific Gravity & $2,6690 \mathrm{gr} / \mathrm{cm}^{3}$ & - & - \\
\hline 3 & Bulk Specific Gravity & $2,6109 \mathrm{gr} / \mathrm{cm}^{3}$ & - & - \\
\hline 4 & Bulk Specific SSD & $2,6327 \mathrm{gr} / \mathrm{cm}^{3}$ & $2,5-2,7 \mathrm{gr} / \mathrm{cm}^{3}$ & Memenuhi syarat \\
\hline 5 & Modulus Halus Butir & 8,3640 & $5-8$ & Memenuhi syarat \\
\hline
\end{tabular}

Tabel 2. Hasil Pengujian Agregat Halus

\begin{tabular}{ccccc}
\hline No & Jenis Pengujian & Hasil Pengujian & Standar & Kesimpulan \\
\hline 1 & Absorbtion & $1 \%$ & - & - \\
\hline 2 & Apparent Specific Gravity & $2,6050 \mathrm{gr} / \mathrm{cm}^{3}$ & - & - \\
\hline 3 & Bulk Specific Gravity & $2,5380 \mathrm{gr} / \mathrm{cm}^{3}$ & - & - \\
\hline 4 & Bulk Specific SSD & $2,5640 \mathrm{gr} / \mathrm{cm}^{3}$ & $2,5-2,7 \mathrm{gr} / \mathrm{cm}^{3}$ & Memenuhi syarat \\
\hline 5 & Modulus Halus Butir & 2,61 & $2,5-2,7$ & Memenuhi syarat \\
\hline 6. & Kandungan Zat Organik & Kuning Muda & Kuning Muda & Memenuhi syarat \\
\hline 7. & Kandungan Lumpur & $2 \%$ & Maksimal $5 \%$ & Memenuhi syarat \\
\hline
\end{tabular}

Tabel 3. Komposisi Kimia Fly Ash

\begin{tabular}{cccccccccc}
\hline $\mathrm{SiO}_{2}$ & $\mathrm{Al}_{2} \mathrm{O}_{3}$ & $\mathrm{Fe}_{2} \mathrm{O}_{3}$ & $\mathrm{TiO}_{2}$ & $\mathrm{CaO}$ & $\mathrm{MgO}$ & $\mathrm{K}_{2} \mathrm{O}$ & $\mathrm{P}_{2} \mathrm{O}_{5}$ & $\mathrm{SO}_{3}$ & $\mathrm{MnO}$ \\
\hline 39,69 & 13,23 & 23,43 & 1,60 & 10,91 & 3,93 & 2,72 & 1,13 & 1,81 & 0,28 \\
\hline
\end{tabular}

Dari hasil pengujian didapat Bulk Specific SSD dari agregat kasar dan halus berturut-turut 2,6327 $\mathrm{gr} / \mathrm{cm}^{3}$ dan 2,5640 gr $/ \mathrm{cm}^{3}$. Nilai tersebut telah memenuhi persyaratan SNI 19702008 yaitu 2,5-2,7 gr/ $\mathrm{cm}^{3}$. Bulk Specific SSD ini akan digunakan untuk perencanaan rancang campur. Selain Bulk Specific SSD, parameter lainnya pada pengujian agregrat telah memenuhi standar yang ada. Pengujian XRF (X-Ray Fluorescence) pada komposisi fly ash menunjukkan bahwa kandungan terbesar yang dimiliki adalah $\mathrm{SiO}_{2}$ sebesar 39,69\%.

\section{Rancang Campur}

Perencanaan rancang campur disesuaikan dengan SNI-03-2384-2000 untuk beton normal dan EFNARC 2002 untuk beton HVFA-SCC (High Volume Fly Ash-Self Compacting Concrete). Kadar cementitious yang digunakan untuk beton HVFA-SCC adalah $500 \mathrm{~kg} / \mathrm{m}^{3}$, sedangkan untuk beton normal adalah $400 \mathrm{~kg} / \mathrm{m}^{3}$. Perbedaan ini dimaksudkan untuk mencapai mutu yang sama antara beton normal dan HVFA-SCC. Rekapitulasi rancang campur masing-masing variasi dapat dilihat pada tabel berikut :

Tabel 4. Rancang Campur Beton High Volume Fly Ash-Self Compacting Concrete dan Beton Normal

\begin{tabular}{cccccccc}
\hline Kode & $\begin{array}{c}\text { Presentase } \\
\text { Fly Ash }\end{array}$ & $\begin{array}{c}\text { Semen } \\
\left(\mathbf{k g} / \mathbf{m}^{3}\right)\end{array}$ & $\begin{array}{c}\text { Fly Ash } \\
\left(\mathbf{k g} / \mathbf{m}^{3}\right)\end{array}$ & $\begin{array}{c}\text { Kerikil } \\
\left(\mathbf{k g} / \mathbf{m}^{3}\right)\end{array}$ & $\begin{array}{c}\text { Pasir } \\
\left(\mathbf{k g} / \mathbf{m}^{3}\right)\end{array}$ & $\begin{array}{c}\text { Air } \\
\left(\mathbf{l t} / \mathbf{m}^{3}\right)\end{array}$ & $\begin{array}{c}\text { Sp } \\
\left(\mathbf{l t} / \mathbf{m}^{3}\right)\end{array}$ \\
\hline HVFA28.50 & $50 \%$ & 250 & 250 & 889,33 & 865,79 & 135 & 10 \\
\hline HVFA28.60 & $60 \%$ & 200 & 300 & 886,79 & 863,19 & 135 & 10 \\
\hline HVFA28.70 & $70 \%$ & 150 & 350 & 884,18 & 860,65 & 135 & 10 \\
\hline NC28 & - & 400 & 0 & 1156,7 & 750,61 & 120 & 4 \\
\hline
\end{tabular}

Hasil Pengujian Berat Volume

Tabel 5. Hasil Pengujian Berat Volume

\begin{tabular}{|c|c|c|c|c|c|}
\hline No. & Benda Uji & $\begin{array}{l}\text { Volume } \\
\left(\mathrm{cm}^{3}\right)\end{array}$ & $\begin{array}{c}\text { Berat } \\
\text { (gr) }\end{array}$ & $\begin{array}{l}\text { Berat volume } \\
\left(\mathrm{kg} / \mathrm{m}^{3}\right)\end{array}$ & $\begin{array}{c}\text { Rata-rata } \\
\left(\mathrm{kg} / \mathrm{m}^{3}\right)\end{array}$ \\
\hline 1 & HVFA28.50.A & 662,68 & 1585 & 2391,8 & \multirow{3}{*}{2396,83} \\
\hline 2 & HVFA28.50.B & 662,68 & 1580 & 2384,26 & \\
\hline 3 & HVFA28.50.C & 662,68 & 1600 & 2414,44 & \\
\hline 4 & HVFA28.60.A & 662,68 & 1590 & 2399,35 & \multirow{3}{*}{2421,98} \\
\hline 5 & HVFA28.60.B & 662,68 & 1615 & 2437,07 & \\
\hline 6 & HVFA28.60.C & 662,68 & 1610 & 2429,53 & \\
\hline 7 & HVFA28.70.A & 662,68 & 1595 & 2406,89 & 2404,38 \\
\hline
\end{tabular}




\begin{tabular}{|c|c|c|c|c|c|}
\hline 8 & HVFA28.70.B & 662,68 & 1580 & 2384,26 & \\
\hline 9 & HVFA28.70.C & 662,68 & 1605 & 2421,98 & \\
\hline 10 & NC28.A & 662,68 & 1629 & 2458,20 & \multirow{3}{*}{2458,20} \\
\hline 11 & NC28.B & 662,68 & 1632 & 2462,73 & \\
\hline 12 & NC28.C & 662,68 & 1626 & 2453,67 & \\
\hline
\end{tabular}

Pengujian berat volume dilakukan untuk mengetahui kepadatan dari campuran tersebut. Dari keempat variasi diatas didapat bahwa nilai berat volume dari masing-masing variasi berkisar $\pm 2400 \mathrm{~kg} / \mathrm{m}^{3}$. Hal ini sesuai dengan SNI-03-2834-2000 bahwa beton memiliki berat volume (2200-2500) $\mathrm{kg} / \mathrm{m}^{3}$.

Hasil Pengujian Beton Segar

Tabel 6. Hasil Pengujian Beton Segar HVFA-SCC

\begin{tabular}{cccccc}
\hline $\begin{array}{c}\text { Jenis } \\
\text { Pengujian }\end{array}$ & Parameter & $\mathbf{5 0 \%}$ & $\mathbf{6 0 \%}$ & $\mathbf{7 0 \%}$ & $\begin{array}{c}\text { Persyaratan Beton SCC } \\
\text { (EFNARC 2002) }\end{array}$ \\
\hline \multirow{2}{*}{ Flow Table } & Diameter $(\mathrm{mm})$ & 658,5 & 674 & 733,5 & $600-700 \mathrm{~mm}$ \\
\cline { 2 - 6 } & $\mathrm{t}_{50}(\mathrm{detik})$ & 4,6 & 4,2 & 3,2 & $2-5$ detik \\
\hline L-Box & $\mathrm{h} 2 / \mathrm{h} 1$ & 0,83 & 0,91 & 0,98 & $0,8-1,0$ \\
\hline \multirow{3}{*}{ V-funnel } & $\mathrm{t}(\mathrm{detik})$ & 10,3 & 8,7 & 7,2 & $6-12$ detik \\
\cline { 2 - 6 } & $\mathrm{T}_{5 \text { menit }}(\mathrm{detik})$ & 11,7 & 10,2 & 9,8 & \\
\cline { 2 - 6 } & $\Delta \mathrm{t}(\mathrm{detik})$ & 1,4 & 1,5 & 2,6 & $0-3$ detik \\
\hline
\end{tabular}

Pada pengujian flow table, penambahan fly ash 50\%, 60\% dan 70\% telah memeuni pesyaratan yaitu persebaran diameter 600-700 mm. Parameter lain yang didapat dari pengujian flow table untuk mengetahui filling ability adalah kecepatan pengaliran, yaitu waktu yang diperlukan beton segar untuk mencapai diameter $50 \mathrm{~cm}$. Hasil penguiian menunjukkan bahwa HVFA-SCC dengan kadar 70\% memiliki waktu yang lebih singkat untuk mencapai diameter sebaran $50 \mathrm{~cm}$ dibandingkan dengan $50 \%$ dan $60 \%$. Hal tersebut terkait dengan semakin banyak penambahan fly ash maka akan meningkatkan ball bearing effect yang berguna untuk mempercapat aliran beton segar. Pengujian LBox dilakukan untuk mengetahui passing ability pada beton segar. Dari ketiga variasi tersebut didapat hasil bahwa perbandingan ketinggian (h2/h1) ketiganya telah memenuhi standar EFNARC 2002 yaitu 0,8-1,0. Jenis pengujian lainnya yang dilakukan adalah $V$-funnel untuk mengetahui filling ability dan segregation resistance. Dapat dilihat dari hasil pengujian $V$-funnel bahwa beton segar HVFA SCC 50\%, 60\%, dan $70 \%$ telah memenuhi persyaratan EFNARC 2002.

\section{Kuat Tekan}

Tabel 7. Hasil Pengujian Kuat Tekan Benda Uji

\begin{tabular}{ccccc}
\hline \multirow{2}{*}{ Parameter } & \multicolumn{4}{c}{ Nama Benda Uji } \\
& HVFA.28.50 & HVFA.28.60 & HVA.28.70 & NC.28 \\
\hline Kuat Tekan $(\mathrm{MPa})$ & 49,86 & 39,16 & 23,71 & 47,78 \\
\hline
\end{tabular}



Gambar 1 Perbandingan Kuat Tekan HVFA-SCC terhadap Beton Normal 
Pengujian kuat tekan dilakukan menggunakan mesin UTM (Universal Testing Machine) di Laboratorium Mesin Universitas Sebelas Maret. Gambar 1 menunjukkan hubungan variasi kadar fly ash terhadap tegangan yang dihasilkan. Hasil pengujian menunjukkan bahwa beton HVFA.28.50 memiliki kuat tekan yang paling tinggi yaitu 49,86 MPa dibanding dengan HVFA.28.60 dan HVFA.28.70 berturut-turut 39,16 MPa dan 23,71 MPa. Sebagai pembanding, kuat tekan beton normal yang dihasilkan adalah 47,78 MPa. Menurunnya kuat tekan diakibatkan semakin banyak penambahan fly ash sebagai subtituen semen maka terjadi penurunan persentase semen sebagai bahan ikat utama dalam beton. Selain itu pada usia 28 hari, reaksi antara fly ash dengan hasil sekunder reaksi hidrasi semen yaitu $\mathrm{Ca}(\mathrm{OH})_{2}$ untuk membentuk C-S-H yang merupakan daya lekat beton belum terjadi secara optimal sehingga membuat kuat tekan beton belum maksimal. Fy ash memiliki dormant period yang cukup lama dan memerlukan $\mathrm{pH}$ diatas 13.3 untuk dapat bereaksi dengan $\mathrm{Ca}(\mathrm{OH})_{2}$. Oleh karena itu, fly ash tidak dapat berkontribusi banyak pada Early Strength Development.

\section{SIMPULAN}

Dari hasil pembahasan diatas dapat diambil beberapa kesimpulan sebagai berikut :

1. Workability beton segar akan meningkat seiring dengan penambahan persentase fly ash.

2. Kuat tekan beton menurun seiring bertambahnya persentase fly ash.

\section{UCAPAN TERIMA KASIH}

Ucapan terima kasih penulis sampaikan kepada Bapak Agus Setiya Budi, S.T., M.T. dan Bapak Ir. Sunarmasto M.T., selaku pembimbing yang dengan penuh kesabaran telah memberi koreksi dan arahan sehingga menyempurnakan penyusunan. Rasa terima kasih penulis sampaikan khusus untuk tim Beton Sabar selaku tim kerja yang pantang menyerah.

\section{REFERENSI}

Andreas Nur Hadi. 2017."'The Effect of Fly Ash Content for Stress-Strain Behavior of High Volume Fly ash - Self Compacting Concrete (HVFA-SCC)". Universitas Sebelas Maret.

Anonim. 2000. "SN1 03-2834-2000, "Tata Cara Pembuatan Rencana Campuran Beton Normal". Badan Standarisasi Nasional, Jakarta.

Anonim. 2004. "SNI 15-2049-2004 Semen Portland". Badan Standardisasi Nasional, Jakarta." Badan Standarisasi Nasional, Jakarta.

Anonim. "Standard Test Method for Passing Ability of Self-Consolidating Concrete by J-Ring", American Society for Testing of Concrete's.". ASTM C 1621M. 1991.

Anonim. "Standard Standard Specification for Concrete Aggregates". ASTM C33. 1991.

Anonim. "Standard Test Method for Compressive Strength of Concrete" , American Society for Testing of Concrete's. ASTM C39/C39M. 1991.

Anonim. "Standard Test Method for Fly Ash and Row or calcined Natural Pozzolan for Use as a mineral Admixture in Portland Cement Concrete", American Society for Testing of Concrete's". ASTM C 618-93. 1991.

Anonim. "Specification and Guidelines for Self - Compacting Concrete". EFNARC. 2002.

Avri Priatma. 2012.”Pengaruh Kadar Fly Ash sebagai Pengganti Sebagian Semen terhadap Kuat Tarik Belah dan Modulus of Rupture pada High Volume Fly Ash-Self Compacting Concrete".Universitas Sebelas Maret.

Davidovits k. 1994b. "Properties of Geopolymer Cements", Proceeding First International Conference on Alkaline Cements and Concrete, Scientific Research Institute on Binders And Materials". Kiev state technical university, kiev, ukraina, hal 131-149.

Dedi Septian. 2011."Effect of Fly Ash Content as Cement Subtitution On Elastic Modulus of High Volume Fly Ash-Self Compacting Concrete". Universitas Sebelas Maret.

Galang Nur Aji Pamungkas. 2017." Influence of Specimen Height to Diameter Ratio (b/d) on The Stress-Strain Response of High Volume Fly Ash Self Compacting Concrete under Uniaxial Compressive Loading". Universitas Sebelas Maret.

Gere and Timoshenko. "Mekanika Bahan”. Erlangga : Jilid II Edisi 4. Jakarta.

Kardiyono Tjokrodimuljo. 1996.”'Teknologi Beton”.Fakultas Teknik Universitas Gadjah Mada. 